\title{
A formação de professores para os anos iniciais do ensino fundamental e para o ensino de história: um estudo com jovens e adultos
}

\author{
Wendel da Silva Marques ${ }^{1}$ \\ Maria Eleusa Montenegro²
}

\section{Resumo}

Este trabalho investigou a formação de professores de História na Educação de Jovens e Adultos. O método utilizado foi a pesquisa qualitativa e o instrumento, a entrevista. Os participantes foram educadores da EJA de uma escola no Distrito Federal. Os principais resultados foram: materiais didáticos inadequados; a falta de formação básica dos educadores; a utilização de diversas fontes para suporte no cotidiano de sala de aula; e a diferenciação do ensino regular para o ensino da EJA. As instituições de educação que trabalham com a EJA têm proporcionado cursos de formação continuada e a troca de experiências entre os educadores.

Palavras-chave: Formação de professores. EJA. Educação de Jovens e Adultos.

\section{Desvelando um problema}

Pensar a formação de professores, a priori, é analisar os objetivos e os conteúdos da formação inicial e observar a atuação da escola, tanto em relação à função social que lhe é peculiar quanto à necessidade de formar profissionais reflexivos.

A perspectiva dessa formação deve sustentar-se nos pilares: aprender a conhecer, aprender a fazer, aprender a viver junto e aprender a ser (UNESCO, 1993), em que se configura a tendência em formação já há alguns anos na comunidade

1 Graduação em Pedagogia, FACE/UniCEUB. Atualmente é professor do Centro de Ensino Mãe Admirável e Centro de Ensino Tiradentes; trabalha com a Educação de Jovens e Adultos.wendelhistoria@yahoo.com.br

2 Pós-doutora em Educação pela Faculdade de Educação da UnB; doutora e mestre em Educação pela UNICAMP; professora aposentada da UFG-Goiás. Atualmente é professora do Curso de Pedagogia/FACES/UniCEUB. memontenegro@terra.com.br 
educacional. Há de se ressaltar também a proposta de nova concepção de educação escolar, a qual redimensiona o papel dos professores e exige formação profissional muito superior à atual.

Para se trabalhar a formação do professor da Educação de Jovens e Adultos (EJA), é necessário profissionalismo daqueles que estejam envolvidos no processo, uma vez que deve haver compreensão quanto às questões que envolvem o trabalho e competência para identificá-las e resolvê-las.

Cabe ressaltar que esse profissionalismo refere-se à capacidade de mobilizar múltiplos recursos, entre os quais os conhecimentos teóricos e as experiências de vida profissional e pessoal. Esse é, na verdade, o grande feedback que o professor da Educação de Jovens e Adultos deve ter com os educandos: trabalhar a partir de experiências já vividas.

Segundo Gadotti (2000, p. 60), a educação básica de jovens e adultos é aquela que possibilita ao educando ler, escrever e compreender a língua nacional, o domínio dos símbolos e as operações matemáticas básicas, além dos conhecimentos essenciais das ciências naturais e sociais e do acesso aos meios de produção cultural, entre os quais o lazer, a arte, a comunicação e o esporte.

Esta pesquisa deve seu início à leitura e à reflexão acerca da Lei de Diretrizes e Bases (1996, p. 11), mais especificamente ao artigo 37, que afirma que o poder público viabilizará e estimulará o acesso e a permanência do trabalhador na escola, ou seja, há, implicitamente, destinação de vagas para aqueles que não tiveram acesso ou oportunidade de continuidade de seus estudos.

A partir de então foram surgindo alguns questionamentos, tais como: quem são os professores da EJA? Qual é a formação deles? E mais especificamente, como se trabalha a disciplina de História nesse segmento, uma vez que também trará ao educando maior significação da realidade da qual ele faz parte?

A pesquisa buscou investigar o ensino de História na Educação de Jovens e Adultos, ou seja, daqueles que trabalham com o $1^{\circ}$ segmento que corresponde ao nível de alfabetização até a quarta série do ensino fundamental.

O trabalho em questão teve como objetivo geral investigar a formação de professores das séries iniciais do Ensino Fundamental em relação ao ensino de História na 
Educação de Jovens e Adultos. Foram objetivos específicos: conhecer a formação dos professores que atuam na Educação de Jovens e Adultos e verificar as metodologias usadas nas aulas de História na Educação de Jovens e Adultos.

\section{Traçando caminhos}

A metodologia que norteou esse trabalho foi a pesquisa qualitativa, que, segundo Flick (2004, p. 56), "enfatiza o fato de que as práticas somente podem ser acessadas através da observação, e de que as entrevistas e as narrativas tornam acessíveis apenas os relatos das práticas e não as próprias práticas”.

Ainda para esse autor, a pesquisa qualitativa pode ser caracterizada como a tentativa de compreensão detalhada dos significados e as características situacionais apresentadas pelos entrevistados, em lugar da produção de medidas quantitativas de características ou comportamentos. Em suma, acredita-se que o pesquisador tem tudo para aprender com pessoas que entrevista.

A pesquisa foi desenvolvida no período de julho de 2005 a julho de 2007, em sete fases, como descrito a seguir.

Na primeira fase, buscou-se a bibliografia da qual se originou tanto o tema quanto os objetivos propostos, o que ocorreu entre os meses de julho e agosto de 2005. A segunda fase constituiu-se pela construção do projeto de pesquisa no período de agosto a setembro de 2005. A terceira fase correspondeu ao aprimoramento do referencial teórico da pesquisa que aconteceu de setembro de 2006 a fevereiro de 2007. A quarta fase objetivou a construção do instrumento de coleta de dados realizada de novembro de 2005 a novembro de 2006. A quinta fase foi de coleta de dados que ocorreu em novembro 2006. A sexta fase foi composta pela análise dos dados coletados de dezembro 2006 a fevereiro 2007. Por fim, a sétima fase correspondeu à construção do relatório final que ocorreu no período de fevereiro de 2007 a março de 2007.

A pesquisa investigou a prática de quatro professores da EJA que trabalham com o $1^{\circ}$ segmento, correspondente às primeiras séries de Ensino Fundamental. 
O instrumento utilizado na pesquisa foi a entrevista semiestruturada. A posição de Flick (2004, p. 56) com relação à entrevista semiestruturada é de que ela traz a expectativa de que é mais provável que os pontos de vistas dos sujeitos sejam expressos em situação de entrevista com um planejamento relativamente aberto que em entrevista padronizada ou por questionário.

Para Witzel (1985 apud FLICK, 2004, p. 56), essa entrevista utiliza especificamente um guia do qual as questões e os estímulos narrativos servirão como dados coletados, sendo possível coletar dados biográficos de determinado problema. Essa entrevista caracteriza-se por três critérios básicos: centralização no problema, ou seja, orientação do pesquisador para um problema social relevante; orientação do objeto, isto é, que os métodos sejam desenvolvidos ou modificados com respeito a um objeto de pesquisa; e, por fim, a orientação no processo de pesquisa e na compreensão do objeto de pesquisa.

Witzel (1985, p. 90) cita como elementos parciais para a entrevista qualificada: o método biográfico, a análise de caso e a discussão em grupo. A concepção de entrevista qualitativa compreende um pequeno questionário precedente, o guia da entrevista, o gravador e o pós-escrito. O guia da entrevista é planejado para auxiliar a corrente narrativa desenvolvida pelo próprio entrevistado, mas, sobretudo, é empregado como base para dar novo rumo à entrevista no caso de conversa estagnante ou de algum tópico improdutivo.

Para a análise de dados ainda foram considerados: o sexo, a idade, a formação acadêmica e o tempo de magistério. E as categorias selecionadas para a organização, análise e discussão dos dados foram:

- Caracterização da clientela;

- Procedimentos metodológicos utilizados;

- Formação profissional;

- Orientações da Secretaria da Educação e da escola para atuação na EJA; e

- Carências para o trabalho. 


\section{Caracterizando os participantes e o cenário}

Todos os participantes da pesquisa são professores do Ensino Fundamental e atuam na Educação de Jovens e Adultos em escolas do Distrito Federal, os quais têm como média a faixa etária entre 22 e 40 anos. Foram entrevistados quatro professores, sendo um do sexo masculino e três do sexo feminino. $O$ tempo de docência variou entre dois a dezessete anos. Confirmou-se que, dos quatro entrevistados, três têm nível superior concluído na área de Pedagogia, e uma entrevistada é graduanda em Pedagogia e concluiu Magistério no Ensino Médio.

O cenário da pesquisa foi uma instituição de ensino governamental localizada no Plano Piloto, Distrito Federal, onde é desenvolvido o Programa de Educação Básica de Jovens e Adultos.

A instituição conta com quatro salas de aula, todas com carteiras de braço, quadro-branco e algumas salas têm TV e vídeo. As salas estão localizadas no subsolo da instituição, são bem conservadas, contudo, algumas apresentam problemas de iluminação e de refrigeração.

\section{Tecendo algumas considerações finais}

As conclusões não ficaram aquém daquilo que se esperava, como o fato de confirmar-se haver certo despreparo por parte dos profissionais da Educação de Jovens e Adultos. Isso ficou demonstrado pela constatação de que as instituições formadoras de educadores não têm se preocupado com a modalidade educacional pesquisada, podendo ser generalizada para o âmbito das políticas públicas educacionais. Quanto aos materiais didáticos, esses, muitas vezes, têm de ser adaptados. Causou surpresa, no entanto, o suporte dado a alguns educadores por parte das escolas, o qual pode ser classificado como bom, pois vem permitindo que os educadores façam parceria com os próprios profissionais da área e concomitantemente com os órgãos de gerência da educação, sendo esses entendidos como a própria direção da escola e a Secretaria de Educação.

Para Pinto (1987, p. 113), a superação da técnica se faz mister com a implantação de nova forma de educação, tendo como arquétipo principal a função social, o que, no entanto, não foi levantado por nenhum dos entrevistados. 
Outra informação relevante foi apresentada pela Secretaria de Educação (1994, p. 17), ao mencionar que grande parte daqueles que trabalham com a EJA não estão preparados para assumir uma classe de jovens e adultos. No levantamento de dados, alguns dos professores enfatizaram preocupação em trabalhar com esse segmento educacional. Assim, de alguma forma, fica expressa uma espécie de medo, quer pela falta de experiência com tal modalidade de educação, quer pelo professor não se sentir preparado para este trabalho. Fica claro na pesquisa que os profissionais da área de educação, pelo menos no Distrito Federal, têm boa qualificação profissional, seja pela graduação superior completa, pelo, estágio de conclusão, ou ainda pela formação continuada. No próprio transcurso da formação dos educadores nas instituições de educação não se verificou nenhuma cadeira específica voltada para essa modalidade educacional, o que se pode levar à conclusão de ser essa uma das grandes causas do despreparo daqueles que atuam nessa área.

No que se refere às metodologias, as afirmações apresentadas pelos participantes vêm ao encontro das idéias colocadas no referencial teórico pelos autores. Segundo Bezerra (2003, p. 113), foram utilizados textos oficiais, gravuras, imagens de heróis, caricaturas, fotos, dentre outros, permitindo ao educando maior apropriação do conhecimento e leitura mais fiel da realidade circundante. Como metodologia apresentada pelos entrevistados, pode-se evidenciar a TV, o texto e a música; mas, mesmo os educadores buscando variar as metodologias, as aulas ainda ficam aquém daquilo que se poderia utilizar como meio de integração do conteúdo com a realidade do educando. Muitas vezes, a metodologia do quadro de giz é o único recurso disponível até mesmo por ser mais prático.

Ao tratar das fontes escritas, em especial das secundárias, os entrevistados emitiram opiniões diferenciadas. Alguns têm a percepção que os materiais são de boa qualidade, mas devem sofrer algum tipo de modificação, pois são inadequados, não atendendo especificamente à clientela da EJA. Outros são mais taxativos e afirmam que são inadequados. Muitos livros utilizados na EJA não passam de compêndios mal elaborados que apresentam o conteúdo de forma fragmentada sob a alegação de ser necessário que o educando dessa modalidade ganhe tempo e de serem desnecessários os pormenores da disciplina em questão.

A principal limitação encontrada durante a elaboração da pesquisa foi a exiguidade do tempo, no tocante ao levantamento de dados e à análise do material levantado. 
Pode-se perceber que o sucesso do professor-pesquisador está na disciplina que ele ministra e na dedicação que tem ao trabalho que desenvolve. Outra limitação foi quanto à utilização do vocabulário específico do pesquisador que vai muito além de saber escrever bem.

Ao término do trabalho, propõem-se, como sugestão para futuras pesquisas, análises mais profundas de livros didáticos utilizados pela EJA e estudos específicos de outros segmentos da modalidade educacional em questão. Sugere-se também pesquisa a respeito da relação professor-aluno na EJA e as consequências dessa relação na aprendizagem.

\title{
Teacher training for the early years of elementary education and History teaching: a study on youth and adults.
}

\begin{abstract}
This paper studied the training of History teachers in Youth and Adult Education. The method employed was qualitative research, using interviews as an instrument. Participants were teachers involved in Youth and Adult Education in a Distrito Federal school. Major findings were: inadequate teaching materials, lack of basic training in educators, the use of assorted sources as support in everyday classroom activities, and the difference between regular teaching and youth and adult education. Teaching institutions that offer Youth and Adult Education have provided continued education courses and the exchange of experience among educators.
\end{abstract}

Keywords: Teacher training. Youth and Adult Education.

\section{Referências}

BRASIL. Ministério da Educação. Secretaria de Educação Fundamental. Diretrizes para uma política nacional de educação de jovens e adultos. Brasília: MEC, 1994.

2001.

. Parâmetros Curriculares Nacionais: História e Geografia. Brasília: MEC, . Parâmetros Curriculares Nacionais: História e Geografia. Brasília: MEC, 2003. 
. Proposta curricular para a educação de jovens e adultos: primeiro segmento: $1^{\text {a }}$ a $4^{\text {a }}$ série. Brasília: MEC, 2002.

. Referenciais para formação de professores. Brasília: MEC, 1999.

FLICK, Uwe. Uma introdução a pesquisa qualitativa. 2. ed. Porto Alegre: Bookmam, 2004.

GADOTTI, Moacir; ROMÃO, José. Educação de jovens e adultos. 2. ed. São Paulo: Cortez, 2000.

GADOTTI, Moacir. Histórias das idéias pedagógicas. São Paulo: Ática, 2000.

KARNAL, Leandro. História na sala de aula: conceitos, práticas e propostas. São Paulo: Contexto, 2003.

PERRENOUD, Philippe. As competências para ensinar no século XXI. Porto Alegre: Artmed, 2002. 